\title{
ANALISIS TINGKAT KERUSAKAN JALAN TOL
}

\author{
Anton Budiharjo $^{1)}$, Dimas Wisnu Haryoko ${ }^{2)}$, Kornelius Jepriadi ${ }^{3)}$ \\ Mohammad Archi Maulyda ${ }^{4}$ ) \\ ${ }^{1,2,3)}$ Manajemen Keselamatan Transportasi Jalan, Politeknik KeselamatanTrasportasi \\ Jalan, Jl. Semeru No.3 Kota Tegal, Jawa Tengah \\ ${ }^{4)}$ FKIP, Universitas Mataram

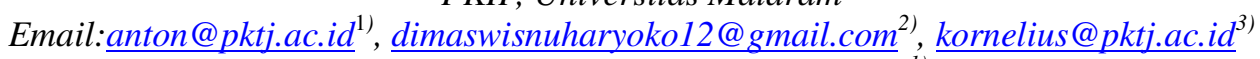 \\ Coresponding Author:anton@pktj.ac.id ${ }^{1}$
}

DOI: http://dx.doi.org/10.29103/tj.v11i1.417

(Received: December 2020 / Revised: January 2021 / Accepted: January 2021)

\begin{abstract}
Abstrak
Jalan Tol Pemalang-Batang merupakan bagian dari jalan tol Tans Jawa yang terbentang sepanjang 39,2 kilometer $(\mathrm{km})$. Jalan Tol merupakan jalan berbayar dan pelayanan harusnya lebih baik dari pada jalan non tol. Selama periode 2019 terdapat kecelakaan sebanyak 182 kejadian dan sempat terjadi jalan retak sepanjang 30 meter. Tujuan dari penelitian ini adalah untuk mengetahui tingkat kerusakan jalan dan apakah ada pengaruh antara Pavement Condition Index (PCI) dan International Roughness Index (IRI) dengan jumlah kejadian kecelakaan. Metode yang digunakan adalah Pavement Condition Index (PCI) atau indeks kondisi perkerasan dan International Roughness Index (IRI) atau indeks ketidakrataan jalan. Hasilnya dengan metode PCI mempunyai nilai rata-rata 94,93 dengan nilai tertinggi 100 dan terendah 16. Sedangkan metode IRI menghasilkan nilai IRI rata-rata 2,48 dengan nilai tertinggi 8,62 dan nilai terendah 0,66 . PCI mempunyai pengaruh $16,67 \%$ terhadap kejadian kecelakaan sedangkan IRI mempunyai pengaruh $0 \%$, dan tidak ada hubungan antara kecelakaan dengan kerusakan jalan khususnya di jalantol Pemalang-Batang.
\end{abstract}

Kata kunci: Jalan Tol,PCI dan IRI, Kecelakaan, Keselamatan Jalan

\begin{abstract}
Pemalang-Batang Toll Road is part of the Trans Java toll road that stretches 39.2 kilometers $(\mathrm{km})$. Toll roads are paid roads and services should be better than non-toll roads. However, in the field, the condition of toll roads is no better than non-toll roads. Accidents happen almost every day with various causes. The purpose of this study was to determine whether there is an influence between the Pavement Condition Index (PCI) and the International Roughness Index (IRI) on the number of accidents, especially on the Pemalang-Batang toll road. The method used is the Pavement Condition Index (PCI) or the index of pavement conditions and the International Roughness Index (IRI) or the road unevenness index. The PCI analysis method shows that the Pemalang-Batang Toll road has an average PCI value of 94.93, the highest PCI is 100 and the lowest PCI is 16 . Whereas in the IRI analysis method it results that the average IRI value is 2.48 , the highest IRI is 8,62 and the lowest IRI was 0.66 . And the relationship with accidents is that PCI has an effect of $16.67 \%$ while IRI has an effect of $0 \%$. The causes of accidents are lack of anticipation, drowsiness, and tire burst
\end{abstract}

Keywords: Toll road,PCI and IRI, accident, road safety

Analisis Tingkat Kerusakan Jalan Tol - Anton Budiharjo, Dimas Wisnu Haryoko, Kornelius Jepriadi 


\section{Latar Belakang}

Pemerintah melalui Kementerian PekerjaanUmum dan Perumahan Rakyat mencanangkan rencana pembangunan jalan tol sepanjang kurang lebih 6000 kilometer hingga tahun 2025 (BPJT, 2018). Jalan tol merupakan salah satu kebutuhan prasarana transportasi jalan yang sangat vital (Suprayitno, 2012), (Budiharjo and Margarani, 2019). Pembangunan infrastruktur jalan tol itu sendiri akan menjadi roda penggerak pertumbuhan ekonomi dan motor pembangunan suatu kawasan. Infrastruktur jalan tol tersebut juga mempunyai peran penting dalam memperkokoh persatuan dan kesatuan bangsa(Wirabrata, 2019).

Di Indonesia ruas jalan tol yang sudah beroperasi sepanjang 1868,62 kilometer (Badan Pengelola Jalan Tol, 2020). Dampak dari pembangunan jalan tol sendiri salah satunya adalah memperlancar lalu lintas, memudahkan distribusi barang dan jasa, meningkatkan perekonomian (Sumaryoto, 2010). Dengan jumlah kendaraan di Indonesia yang meningkat secara signifikan di mana pada tahun 2008 hanya terdapat 61.685.063 kendaraan namun pada tahun 2018 jumlah kendaraan menjadi 146.858.759 kendaraan (Badan Pusat Statistik, 2019). Pembangunan jalan tol merupakan solusi yang diberikan oleh Pemerintah Pusat dengan merangkul pihak swasta untuk membangun ruas jalan tol (Badan Pengelola Jalan Tol, 2020).

Jalan tol sendiri merupakan jalan alternatif dan dapat memberikan pelayanan lebih dibandingkan jalan umum non tol karena penggunanya dikenakan biaya penggunaan tol tersebut (Zuna, 2016). Salah satunya adalah kondisi perkerasan jalan yang baik, namun tetap saja pada ruas jalan tol tertentu di Indonesia masih terdapat kerusakan jalan dan tidak ada bedanya dengan jalan umum.

Kerusakan jalan tersebut dapat diatasi apabila operator jalan tol (Badan Usaha Jalan Tol/BUJT) telah mematuhi Standar Pelayanan minimal (SPM) jalan tol. Kejadian kecelakaan akibat pecah ban yang diakibatlan oleh jalan berlubang masih terjadi di jalan tol (oto.detik.com, 2020). Jalan tol merupakan jalan berbayar, seharusnya pelayanan jalan lebih baik dari pada jalan umum non tol. Sehingga operator jalan tol tidak melulu mencari keuntungan, tetapi juga mengutamanakan keselamatan dan kelancaran lalu lintas. Karena bisnis utama jalan tol adalah keselamatan dan kelancaran.

Jalan Tol Pemalang-Batang merupakan salah satu ruas jalan tol Trans Jawa yang membentang di sepanjang jalur pantai utara jawa dan menghubungkan antara ruas jalan tol Pejagan-Pemalang dengan ruas jalan tol Semarang-Batang. Jalan Tol ini mempunyai Panjang 39,2 kilometer dengan 3 akses masuk dan keluar, yaitu akses Gandulan yang berada di Kabupaten Pemalang, akses Bojong yang berada di Kabupaten Pekalongan serta akses Setono yang berada di kota Pekalongan. Data dari PT. Pemalang Batang Toll Road (PT. PBTR) menyebutkan bahwa selama periode bulan November 2018-Desember 2019 telah terjadi kecelakaan sebanyak 182 kejadian. Penyebab kecelakaan lalu lintas beragam, mulai dari pecah ban, mengantuk, kurang antisipasi dan lain-lain. Berdasarkan data yang ada di bulan Januari 2019 pernah terjadi retak pada badan jalan sepanjang 30 meter pada kilometer 321 .

Beberapa penelitian sebelumnya telah membahas mengenai kerusakan jalan, antara lain penelitian dari (Rahmawati et al., 2018) yang dilakukan di Kota Kebumen menyatakan bahwa untuk meningkatkan umur layanan perkerasan, dapat dilakukan dengan membatasi dan mengelola beban kendaraan yang 
diijinkan pada jalan tersebut. Penelitian tersebut menggunakan metode Austroads dan Asphalt Institute serta dianalisis menggunakan program Kenpave. Selain itu dalam penelitian lainnya (Faisal et al., 2020) membandingkan metode Bina Marga dan Pavement Condition Index (PCI) dalam mengevaluasi kerusakan jalan di Aceh Besar dengan hasil bahwa metode Bina Marga dan Metode PCI hasilnya relative sama. Demikian juga penelitian dari (Wirnanda, Anggraini and Isya, 2018) di Aceh dengan hasil nilai Pavement Condition Index (PCI) berbading lurus dengan kerusakan jalan. Dari penelitian sebelumnya hanya membahas terkait kerusakan jalan dan belum menghubungkan dengan factor kecelakaan lalu lintas.

Berdasarkan permasalahan yang telah diuraikan tersebut, maka penelitian ini bertujuan menganalisis tingkat kerusakan jalan tol khususnya jalan tol PemalangBatang sepanjang 39,2 kilometer dan pengaruhnya terhadap kejadian kecelakaan, baik di jalur A dan B. Dari hasil penelitian ini diharapkan dapat bermanfaat bagi kepentian dunia akademisi yaitu dapat memperkaya kajian mengenai kerusakan jalan serta dapat bermanfaat bagi operator jalan tol guna perbaikan jalan sehingga tercipta keselamatan, kelancaran dan kenyamanan pengguna jalan tol

\section{Metode Penelitian}

Lokasi penelitian berada di jalan tol Pemalang-Batang sepanjang 39,2 kilometer. Metode penelitian yang pertama adalah persiapan dimulai melakukan rumusan masalah yang didapat dari lokasi penelitian. Selanjutnya menentukan maksud dan tujuan dari penelitian, kemudian mencari literasi yang berkaitan dengan penelitian ini. Tahap kedua, dilanjutkan dengan pengumpulan data yang diperlukan. Terdapat dua jenis data yang dicari yaitu data primer dan data sekunder. Data primer meliputi kondisi perkerasan jalan (PCI) dan nilai ketidakrataan jalan (IRI). Sedangkan data sekunder meliputi peta lokasi penelitian, nama ruas jalan, panjang ruas jalan, jenis perkerasan jalan, tipe ruas jalan, lebar ruas jalan. Tahap ketiga adalah tahap analisa data dari lokasi penelitian yang meliputi tahap pengolahan data yang dilanjutkan menjadi analisa kerusakan jalan dengan metode PCI dan analisa kerusakan jalan dengan metode IRI. Sedangkan pelaksanaan survey menggunakan kendaraan survei Hawkeye 2000 Series.

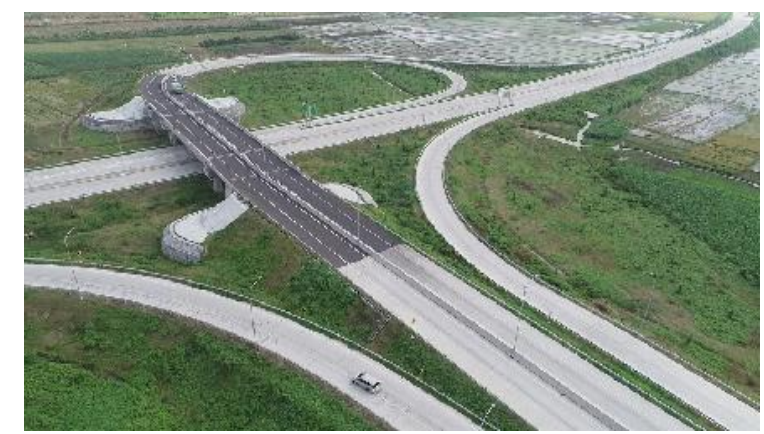

Gambar 1 Jalan tol Pemalang-Batang (http://pbtr.co.id/v2/galeri, 2020)

Alat dalam teknologi Hawkeye 2000 Series yang digunakan dalam pengambilan data PCI dan IRI berupa Pavement Camera, GPS, DMI serta Laser Profiler. Pavement Camera merupakan alat yang digunakan dalam mencari variabel data berupa patholing, cracking (kerusakan jalan) yang menghasilkan 
output berupa citra foto interaktif. GPS merupakan alat yang digunakan dalam mencari variable data berupa posisi geografis dan referensi yang menghasilkan output berupa tabulasi dan grafik. DMI merupakan alat yang digunakan dalam mencari variabel data berupa referensi jarak yang menghasilkan output berupa tabulasi dan grafik. Laser Profiler merupakan alat yang digunakan dalam mencari variabel data berupa roughness dan rutting (ARRB Group, 2016).

Sebelum survey dilakukan hal yang pertama adalah mengkalibrasi mobil survei Hawkeye 2000 Series. Kalibrasi merupakan simulasi dari pengemudi pada permukaan datar dengan kecepatan $80 \mathrm{~km} / \mathrm{jam}$, permukaan datar yang sempurna memiliki nilai IRI 0 (nol), mengguncang kendaraan untuk memeriksa apakah akselerometer dan laser berfungsi secara terintegrasi. Tujuan dari dilakukan kalibrasi adalah untuk mengoreksi kalibrasi laser dan akselerometer yang sejajar dengan roda, mengkoreksi semua laser berfungsi dengan baik dan memastikan keakuratan roughness, rutting dan texture. Pelaksanaan survey dilakukan dengan jumlah anggota yang dibutuhkan setidaknya tiga orang (pengemudi, operator komputer dan anggota cadangan), survey dilakukan pada siang hari karena jika survey dilakukan pada malam hari keluaran yang dihasilkan kurang jelas. Proses survey dilakukan dengan kecepatan di atas $20 \mathrm{~km} / \mathrm{jam}$ karena sensor laser akan optimal jika berada pada kecepatan di atas $20 \mathrm{~km} / \mathrm{jam}$, apabila berada pada kecepatan $20 \mathrm{~km} / \mathrm{jam}$ sensor akan mati (Samsuri et al., 2019). Prosedur surveynya menggunakan kendaraan hawkeye 2000 sesuai panduan buku manual dari (ARRB Group, 2016).

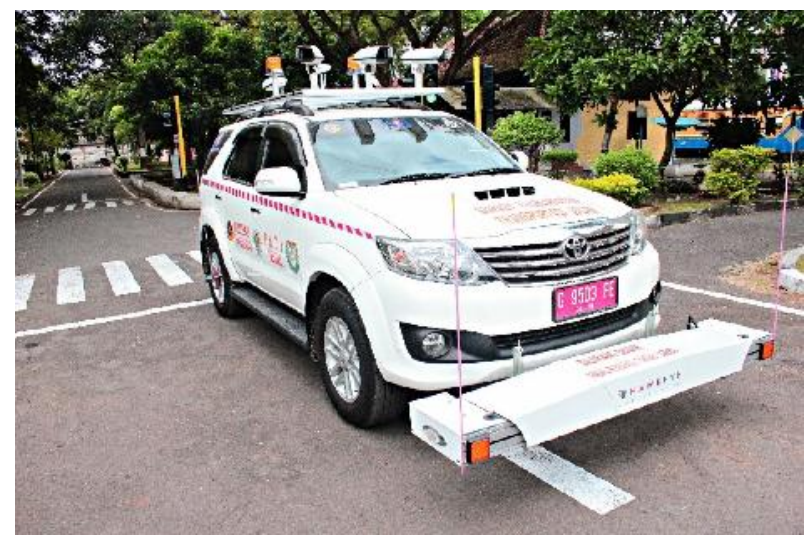

Gambar 2 Mobil survey hawkeye 2000

Sedangkan Pengumpulan data sekunder didapatkan dari operator jalan tol Pemalang-Batang (PT. PBTR) yang memiliki kewenangan terkait operasional jalan tol dan pendataan sehingga dapat dipertanggungjawabkan. Data yang dibutuhkan adalah peta lokasi studi, nama ruas jalan, panjang ruas jalan, jenis perkerasan jalan, tipe ruas jalan dan lebar ruas jalan.

Density atau kerapatan kerusakan adalah prosentase luas atau panjang total dari suatu jenis kerusakan terhadap luas atau panjang total bagian jalan yang diukur, bias dalam meter persegi atau dalam meter. Untuk menghitung nilai density dipakai rumus:

$$
\text { Density }=\frac{A d}{A s} \text { atau } \frac{L d}{A s}
$$


di mana

Ad : Luas total jeniskerusakanuntuktiaptingkatkerusakan $\left(\mathrm{m}^{2}\right)$

Ld : Panjang total jeniskerusakanuntuktiaptingkatkerusakan (m)

As : Luas total unit segmen $\left(\mathrm{m}^{2}\right)$

Deduct Value merupakan nilai pengurangan untuk tiap jenis kerusakan yang diperoleh dari kurva hubungan antara density dan deduct value (Ramli, Isya and Saleh, 2018). Deduct value juga dibedakan atas tingkat kerusakan untuk tiap-tiap jenis kerusakan.

- Total Deduct Value (TDV)

Total Deduct Value (TDV) adalah nilai total dari individual deduct value untuk tiap jenis kerusakan dan tingkat kerusakan yang ada pada suatu unit penelitian.

- $\quad$ Corrected Deduct Value (CDV)

Corrected Deduct Value (CDV) adalah diperoleh dari kurva hubungan antara nilai TDV dan nilai CDV dengan pemilihan lengkung kurva sesuai dengan jumlah nilai individual deduct value yang mempunyai nilai lebih besar dari 2 (dua).

Jika nilai CDV telah diketahui, maka nilai PCI tiap unit diketahui dengan rumus:

$$
P C I(s)=100-C D V
$$

di mana

PCI(s) : Pavement Condition Index untuktiap unit.

CDV : Corrected Deduct Value untuktiap unit.

Metode PCI memberikan informasi kondisi perkerasan hanya pada saat survey dilakukan, tapi tidak dapat memberikan gambaran prediksi di masa datang. Namun demikian, dengan melakukan survey kondisi secara periodik, informasi kondisi perkerasan dapat berguna untuk prediksi kinerja di masa datang, selain juga dapat digunakan sebagai masukan pengukuran yang lebih detail (Karim, Rubasi and Saleh, 2016). Penilaian tingkat kerusakan jalan berdasarkan PCI dapat dilihat pada Tabel 1.

Tabel 1 Penilaian Pavement Condition Index (PCI)

\begin{tabular}{cl}
\hline Nilai $P C I$ & \multicolumn{1}{c}{ Kondisi } \\
\hline $86-100$ & Baik(Good) \\
\hline $71-85$ & Memuaskan(Satisfactory) \\
\hline $56-70$ & Sedang(Fair) \\
\hline $41-55$ & Buruk(Poor) \\
\hline $26-40$ & SangatBuruk(Very Poor $)$ \\
\hline $11-25$ & Parah(Serious) \\
\hline $0-10$ & Gagal(Failed $)$ \\
\hline
\end{tabular}

Nilai IRI digunakan untuk mengetahui dan mengevaluasi kondisi kemantapan permukaan infrastruktur jalan (Pembuain, Priyanto and Suparma, 2019). Ketidakrataan merupakan gambaran profil memanjang dari perkerasan yang merupakan gambaran dari kenyamanan berkendara pada jalan raya. Nilai kuantitatif ketidakrataan ini dinyatakan dalam IRI (International Roughness Index), yaitu panjang kumulatif naik turun permukaan per satuan panjang di mana pada satuan IRI dinyatakan dalam meter turun naik perkilometer panjang jalan 
$(\mathrm{m} / \mathrm{km})$. Tingkat ketidakrataan merupakan salah satu faktor/fungsi pelayanan (functional performance) dari suatu perkerasan jalan yang berpengaruh pada kenyamanan pengemudi (riding quality). Kualitas jalan yang ada maupun yang akan dibangun harus sesuai dengan standar yang berlaku. Kerataan permukaan jalan dianggap sebagai hasil kondisi perkerasan secara menyeluruh. Jika cukup rata, maka jalan dianggap baik mulai dari lapisan paling bawah sampai lapisan atas perkerasan jalan dan juga sebaliknya (Zhao and Nagayama, 2017).

Tabel 2 Nilai IRI untuk jalan beraspal

\begin{tabular}{|c|c|c|}
\hline No & $\begin{array}{c}\text { Skala IRI } \\
(\mathrm{m} / \mathrm{km})\end{array}$ & Karakteristik \\
\hline 1 & $\begin{array}{c}0-2 \\
(\text { Excellent })\end{array}$ & $\begin{array}{l}\text { Kecepatan berkendara melebihi } 120 \mathrm{~km} / \mathrm{jam} \text {. Hampir tidak ada goncangan } \\
\text { pada kecepatan } 80 \mathrm{~km} / \mathrm{jam} \text { dengan nilai } I R I \text { berkisar antara } 1.3-1.8 \text {. } \\
\text { Lubang dan kerutan pada jalan terlihat, jalan yang amblas }<2 \mathrm{~mm} / 3 \mathrm{~m}\end{array}$ \\
\hline 2 & $\begin{array}{c}2-4 \\
(\text { Good) }\end{array}$ & $\begin{array}{l}\text { Kecepatan berkendara antara } 100-120 \mathrm{~km} / \mathrm{jam} \text {. Pada kecepatan } 80 \mathrm{~km} / \mathrm{jam} \text {, } \\
\text { terasa cukup gonjangan akibat gelombang pada perkerasan. Kerusakan jalan } \\
\text { seperti: amblas, tambalan dan lubang (dengan kedalaman } 5-15 \mathrm{~mm} / 3 \mathrm{~m} \text { atau } \\
10-20 \mathrm{~mm} / 5 \mathrm{~m} \text { dengan frekuensi } 2-1 \text { per } 50 \text { meter, atau banyak lubang } \\
\text { yang dangkal. Perkerasan tanpa kerusakan seperti: kerutan (corrugation) } \\
\text { dengan ukuran sedang atau gelombang yang cukup besar }\end{array}$ \\
\hline 3 & $\begin{array}{l}4-6 \\
\text { (Fair) }\end{array}$ & $\begin{array}{l}\text { Kecepatan berkendara bekisar antara } 70-90 \mathrm{~km} / \mathrm{jam} \text {, goncangan dapat } \\
\text { dengan jelas dirasakan. Biasanya dikaitkan dengan kerusakan seperti: sering } \\
\text { didapati permukaan yang amblas serta tambalan (biasanya berukuran } 15- \\
20 \mathrm{~mm} / 3 \mathrm{~m} \text { atau } 20-30 \mathrm{~mm} / 5 \mathrm{~m} \text { dengan frekuensi } 5-3 \text { per } 50 \text { meter) dan } \\
\text { juga kadang didapati lubang (biasanya } 5-3 \text { per } 50 \text { meter). Perkerasan tanpa } \\
\text { kerusakan seperti: gelombang atau kerutan yang cukup besar }\end{array}$ \\
\hline 4 & $\begin{array}{c}6-8 \\
(\text { Poor })\end{array}$ & $\begin{array}{l}\text { Kecepatan berkendara bekisar antara } 50-60 \mathrm{~km} / \mathrm{jam} \text {, goncangan semakin } \\
\text { terasa. Terdapat kerusakan yang cukup parah seperti: banyak ditemui } \\
\text { penurunan yang cukup dalam dan tambalan (biasanyaberukuran } 20-40 \\
\mathrm{~mm} / 3 \mathrm{~m} \text { atau } 40-80 \mathrm{~mm} / 5 \mathrm{~m} \text { dengan frekuensi } 5-3 \text { per } 5 \text { meter) atau lubang } \\
\text { yang sering didapati (biasanya } 4-6 \text { per } 50 \text { meter) }\end{array}$ \\
\hline 5 & $\begin{array}{c}8-10 \\
\text { (Very Poor) }\end{array}$ & $\begin{array}{l}\text { Kecepatan kendaraan di bawah } 50 \mathrm{~km} / \mathrm{jam} \text {. Banyak didapati jalan yang } \\
\text { amblas, lubang dan kerusakan yang sangat parah (biasanya dengan } \\
\text { kedalaman } 40-80 \mathrm{~mm} \text { dengan frekuensi } 8-16 \text { per } 50 \text { meter) }\end{array}$ \\
\hline
\end{tabular}

\section{Hasil dan Pembahasan}

Dari hasil survey menggunakan kendaraan survey hawkeye 2000 series, didapatkan hasil kerusakan jalan pada tahun 2019 bulan November yang paling banyak adalah tambalan dengan skala kerusakan rendah, sedang sampai tinggi. Demikian juga kerusakan berupa retak menduduki peringkat kedua setelah tambalan seperti diperlihatkan pada Tabel 3.

Tabel 3 Kerusakan jalan

\begin{tabular}{ccc}
\hline JenisKerusakan & Tingkat Kerusakan & JumlahKerusakan \\
\hline RetakKulitBuaya & High & 2 \\
\hline RetakKulitBuaya & Medium & 1 \\
\hline Lubang & High & 10 \\
\hline Lubang & Medium & 8 \\
\hline Lubang & Low & 1 \\
\hline Tambalan (PerkerasanLentur) & High & 109 \\
\hline Tambalan (PerkerasanLentur) & Medium & 47 \\
\hline Tambalan (PerkerasanLentur) & Low & 19 \\
\hline
\end{tabular}

Analisis Tingkat Kerusakan Jalan Tol - Anton Budiharjo, Dimas Wisnu Haryoko, Kornelius Jepriadi 


\begin{tabular}{ccc}
\hline Amblas & High & 5 \\
\hline Amblas & Medium & 9 \\
\hline Amblas & Low & 2 \\
\hline PelepasanButiran & High & 5 \\
\hline PelepasanButiran & Medium & 3 \\
\hline Kegemukan & Medium & 1 \\
\hline Kegemukan & Low & 1 \\
\hline RetakSudut & High & 5 \\
\hline RetakSudut & Medium & 4 \\
\hline Retak Linear & High & 41 \\
\hline Retak Linear & Medium & 60 \\
\hline Retak Linear & Low & 1 \\
\hline Pecah & Medium & 1 \\
\hline Pecah & Low & 1 \\
\hline Tambalan (Perkerasan Kaku) & High & 4 \\
\hline Tambalan (Perkerasan Kaku) & Low & 5 \\
\hline
\end{tabular}

Tabel 4 PCI Rating Scale

\begin{tabular}{ccc}
\hline Predikat & Jumlah Stationer & Prosentase \\
\hline Good & 1446 & $91.98 \%$ \\
\hline Fair & 70 & $4.45 \%$ \\
\hline Poor & 56 & $3.56 \%$ \\
\hline
\end{tabular}

Hasil rating scale PCI pada ruas jalan Tol secara umum masih tergolong baik (good) dengan prosentase 91,98\% dengan jumlah stationer 1446, sedangkan hasil buruk (poor) dengan prosentase $3.56 \%$ dengan jumlah stationer 56 titik.

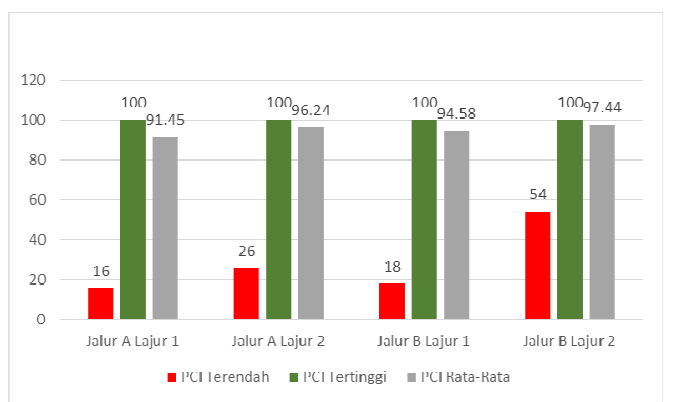

Gambar 3 Nilai PCI tiap lajur

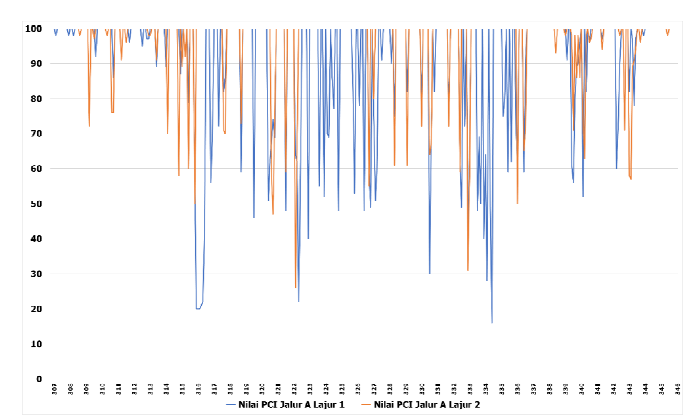

Gambar 4 Nilai PCI jalur A

Analisis Tingkat Kerusakan Jalan Tol - Anton Budiharjo, Dimas Wisnu Haryoko, Kornelius Jepriadi 
Dari hasil tersebut mengindikasikan bahwa masih terdapat ruas jalan yang buruk tidak sesuai dengan SPM jalan tol meskipun nilainya kecil. Hasil PCI secara umum mempunyai nilai rata-rata sebesar 94,93 yang mempunyai arti bahwa pada ruas jalan Tol memiliki rata-rata predikat PCI dengan kondisi Good (baik), di mana nilai PCI tertinggi sebesar 100 sedangkan nilai PCI terendah sebesar 16, seuai dengan Gambar 3. Sedangkan nilai PCI pada masing-masing jalur dan lajur dapat dilihat pada Gambar 4 dan Gambar 5.

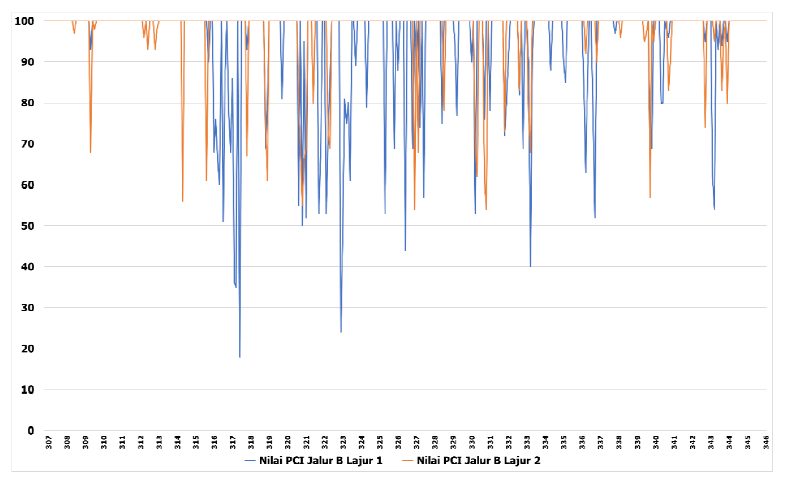

Gambar 5Nilai PCI jalur B

Tabel 5 Sampel stationer dan hasilnya

\begin{tabular}{|c|c|c|c|}
\hline \multirow{2}{*}{$\begin{array}{c}\text { No } \\
1\end{array}$} & \multicolumn{2}{|c|}{ Lokasi } & \multirow[t]{2}{*}{ Dokumentasi } \\
\hline & Jalur & : A & \\
\hline & Lajur & $: 1$ & \\
\hline & Stationer & $: 317+300$ & \\
\hline & Nilai PCI & $: 72$ & \\
\hline & PredikatPCI & : Good & \\
\hline & Keterangan & : Baik & \\
\hline 2 & Jalur & $: \mathrm{A}$ & \\
\hline & Lajur & $: 2$ & \\
\hline & Stationer & $: 322+200$ & \\
\hline & Nilai PCI & $: 66$ & \\
\hline & Predikat PCI & : Fair & \\
\hline & Keterangan & : Sedang & \\
\hline 3 & Jalur & : B & \\
\hline & Lajur & $: 1$ & \\
\hline & Stationer & $: 317+400$ & \\
\hline & Nilai PCI & $: 18$ & \\
\hline & Predikat PCI & : Very poor & \\
\hline & Keterangan & : Buruk & \\
\hline
\end{tabular}

Stationer jalan dengan predikat PCI kondisi buruk adalah stationer jalan yang mempunyai nilai di bawah 55. Predikat PCI buruk merupakan prioritas yang harus dilakukan perbaikan guna meningkatkan keselamatan dan kenyamanan jalan pada ruas jalan Tol dengan kerusakan jalan antara lain lubang, tambalan yang tidak rata dan retak. Hasil analisis International Roughness Index (IRI) yang 
digunakan dalam penelitian ini berpedoman pada ASTM E 1926 dan Standar Pelayanan Minimal Jalan Tol. Dua metode tersebut digunakan untuk melihat hasil yang lebih detail. Hasil IRI metode ASTM E 1926 dapat dilihat pada Tabel 4.

Tabel 6 Hasil IRI sesuai ASTM E 1962

\begin{tabular}{ccc}
\hline Predikat & Jumlah Stationer & Prosentase \\
\hline Excellent & 592 & $37.66 \%$ \\
\hline Good & 840 & $53.44 \%$ \\
\hline Fair & 135 & $8.59 \%$ \\
\hline Poor & 4 & $0.25 \%$ \\
\hline Failed & 1 & $0.06 \%$ \\
\hline
\end{tabular}

Analisis hasil IRI sesuai SPM jalan tol menunjukkan predikat Poor mencapai $8,91 \%$ dengan jumlah stationer 140 . Artinya masih terdapat jalan yang rusak tidak sesuai dengan SPM jalan tol. Baik hasil IRI dengan metode ASTM E 1962 maupun dengan metode sesuai SPM Jalan Tol sebenarnya hampir sama, hanya saja untuk metode sesuai SPM Jalan Tol lebih disederhanakan, yaitu nilai $\leq$ $4 \mathrm{~m} / \mathrm{km}$ dikatakan baik dan memenuhi, sedangkan apabila nilai IRI $>4 \mathrm{~m} / \mathrm{km}$ dikatakan tidak memenuhi SPM.

\begin{tabular}{ccc}
\multicolumn{3}{c}{ Tabel 7 Hasil IRI sesuai SPM jalan tol } \\
\hline Predikat & Jumlah Stationer & Prosentase \\
\hline Good & 1432 & $91.09 \%$ \\
\hline Poor & 140 & $8.91 \%$ \\
\hline
\end{tabular}

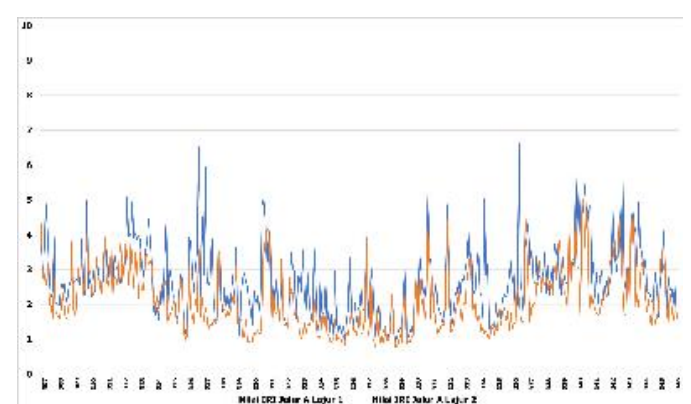

Gambar 6Nilai IRI jalur A

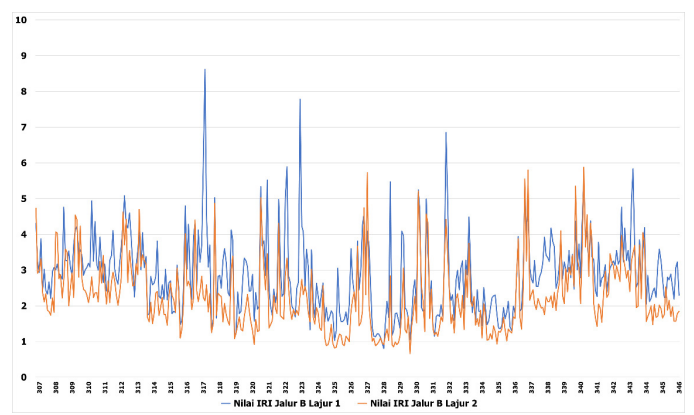

Gambar 7Nilai IRI jalur B 
Hasil nilai IRI pada ruas jalan secara umum mempunyai nilai rata-rata sebesar 2,48 yang mempunyai arti bahwa pada ruas jalan memiliki rata-rata predikat IRI dengan kondisi Good (baik), di mana nilai IRI tertinggi pada sebesar 8,62 sedangkan nilai IRI terendah sebesar 0,66.

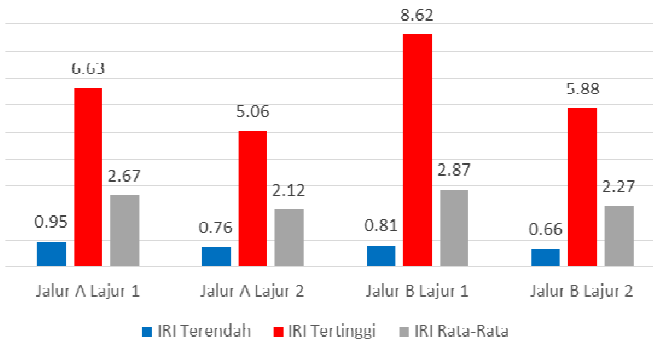

Gambar 8 Nilai IRI tiap lajur

Nilai indeks ketidakrataan jalan (IRI) rata-rata sebesar 2,48 yang mempunyai arti bahwa ruas jalan Tol mempunyai kondisi ketidakrataan jalan yang baik. Dengan nilai indeks ketidakrataan tertinggi sebesar 8,62 sedangkan nilai indeks ketidakrataan terendah sebesar 0,66. Hal ini berarti masih terdapat beberapa ruas yang kondisi jalannya tidak rata, meskipun sedikit. Tidak rata tersebut bias karena tambalan, lubang ataupun joint dengan jembatan.

Hasil analisis kejadian kecelakaan yang telah dilakukan mengacu pada lokasi-lokasi mana yang sering terjadi kecelakaan atau lebih sering dikenal dengan Daerah Rawan Kecelakaan (DRK). Daerah rawan kecelakaan menurut (Salamah, Rabbani and Budiharjo, 2018) dibagi menjadi 3, yaitu lokasi rawan kecelakaan (hazardous sites), rute rawan kecelakaan (hazardous routes) dan area/wilayah rawan kecelakaan (hazardous area). Sedangkan blackspot merupakan lokasi rawan kecelakaan dengan Panjang 300 m sampai dengan 1 kilometer (Idris and Santoso, 2004). Data kecelakaan yang digunakan dalam penelitian inia dalah data kecelakaan di mana terakhir kali dilakukan perbaikan sebelum survey dilakukan. Tanggal survey guna mengambil data primer dilakukan pada 18 Desember 2019 sedangkan perbaikan terkahir sebelum dilakukan survey guna mengambil data primer dilakukan pada tanggal 10 Desember 2019.

Dalam kurun waktu 8 hari terjadi 6 kejadian kecelakaan di ruas jalan Tol Pemalang-Batang. Dari Tabel 8 dapat diketahui bahwa masing-masing jalur terdapat blackspot.

Tabel 8 Lokasi Rawan Kecelakaan

\begin{tabular}{cccc}
\hline Jalur & Stationer & Keterangan & Rank \\
\hline A1 & $323+800$ & Blackspot & 1 \\
\hline A2 & $317+200$ & Blackspot & 1 \\
\hline A2 & $327+800$ & Blackspot & 1 \\
\hline B1 & $314+600$ & Blackspot & 1 \\
\hline B1 & $314+800$ & Blackspot & 1 \\
\hline B2 & $335+400$ & Blackspot & 1 \\
\hline
\end{tabular}


Penyebab kecelakaan adalah kurang antisipasi, ngantuk dan pecah ban. Kurang antisipasi paling banyak karena tidak bias menguasai kendaraan karena berbagai faktor. Dari 6 kejadian kecelakaan terdapat 3 lokasi/stationer jalan yang mungkin terdapat potensi disebabkan oleh kerusakan jalan yakni pada KM $323+800$, KM 327+800 dan 335+400. Pada KM 323+800 terdapat kerusakan jalan berupa tambalan pada perkerasan lentur. KM 327+800 terdapat kejadian kecelakaan yang terjadi cuaca mendung, dengan ditemukan beberapa sampah di sekitar lubang drainase dapat menjadi potensi air hujan tersumbat dan berpotensi hydro planing (tergelincir). KM $335+400$ di mana terdapat perbedaan tinggi antara jembatan dan perkerasan jalan yang membuat kendaraan mengalami efek bumping dan melayang, terlebih jika kendaraan dipacu melebihi batas kecepatan yang disarankan, hal ini juga sejalan dengan penelitian dari (Pradana, Budiman and Andriyani, 2013) di jalan tol SerangTimur-Merak dengan hasil bahwa kecelakaan lalu lintas di lokasi tersebut disebabkan oleh kurangnya antisipasi dari para pengguna jalan/pengendara dan kecepatan tinggi yang melebihi batas kecepatan yang ditetapkan, serta penelitian dari (Fahza and Widyastuti, 2019) di jalan tol Surabaya-Gempol dengan hasil bahwa penyebab kecelakaan lalu lintas di lokasi jalan tol tersebut yaitua kibat kesalahan manusia (human error) antara lain mengantuk dan lelah (fatique).

Tabel 9 Penyebab kecelakaan

\begin{tabular}{ccccc}
\hline Stationer & Jalur & Lajur & Cuaca & PenyebabKecelakaan \\
\hline $323+800$ & A & 1 & cerah & kurangantisipasi \\
\hline $317+200$ & A & 2 & cerah & kurangantisipasi \\
\hline $327+800$ & A & 2 & mendung & kurangantisipasi \\
\hline $314+600$ & B & 1 & cerah & ngantuk \\
\hline $314+800$ & B & 1 & cerah & ngantuk \\
\hline $335+400$ & B & 2 & hujan & Pecah ban \\
\hline
\end{tabular}

Tabel 10 Hubungan kecelakaan dengan PCI dan IRI

\begin{tabular}{ccccc}
\hline Stationer & Jalur & Lajur & Predikat PCI & Predikat IRI \\
\hline $314+600$ & B & 1 & Baik & Baik \\
\hline $314+800$ & B & 1 & Baik & Baik \\
\hline $317+200$ & A & 2 & Baik & Baik \\
\hline $323+800$ & A & 1 & Buruk & Baik \\
\hline $327+800$ & A & 2 & Baik & Baik \\
\hline $335+400$ & B & 2 & Baik & Baik \\
\hline
\end{tabular}

Dari 6 kejadian kecelakaan, terdapat 5 kejadian kecelakaan dengan 5 stationer jalan yang mempunyai predikat good sesuai denganr PCI. Sedangkan hanya 1 stationer jalan yang mempunyai predikat buruk/Poor. Dengan demikian PCI mempunyai pengaruh terhadap kejadian kecelakaan sebesar 16,67\% sedangkan 83,33\% diakibatkan oleh factor lain.

Begitu pula dengan IRI, dari total kecelakaan yang terjadi berjumlah 6 kejadian kecelakaan, 2 stationer jalan mempunyai predikat IRI menurut ASTM E 1926 adalah Good dan 4 stationer jalan mempunyai predikat Excellent sedangkan 6 kejadian kecelakaan terdapat 6 stationer jalan yang mempunyai predikat IRI menurut Standar Pelayanan Minimal Jalan Tol adalah Good. 
Hal ini berarti bahwa kejadian kecelakaan yang terjadi tidak ada hubungannya dengan kondisi IRI yang buruk. Dengan demikian dapat dikatakan bahwa kecelakaan di ruas jalan tol Pemalang-Batang selama periode penelitian tidak ada hubungnnya dengan kondisidari Pavement Condition Index (PCI) dan International Roughness Index (IRI).

Tabel 11 Hasil uji korelasi IRI dan PCI

\begin{tabular}{clcc}
\hline & Correlations & IRI & PCI \\
\hline \multirow{2}{*}{ IRI } & Pearson Correlation & 1 & -0.076 \\
\cline { 2 - 4 } & Sig. (2-tailed) & & 0.221 \\
\cline { 2 - 4 } & $\mathrm{N}$ & 265 & 265 \\
\hline PCI & Pearson Correlation & -0.076 & 1 \\
\cline { 2 - 4 } & Sig. (2-tailed) & 0.221 & \\
\cline { 2 - 4 } & $\mathrm{N}$ & 265 & 265 \\
\hline
\end{tabular}

Hasil analisis korelasi sederhana (r) didapatkan korelasi antara PCI dengan IRI (r) adalah 0,076. Hal ini menunjukkan bahwa terjadi hubungan yang lemah antara PCI dan IRI. Sedangkan arah hubungan adalah negative karena nilai $r$ negatif, berarti semakin tinggi nilai PCI maka nilai IRI akan semakin rendah atau semakin banyak kerusakan jalan maka stationer jalan tersebut akan mempunyai kondisi permukaan jalan yang semakin tidak rata, namun apabila suatu stationer jalan tidak mempunyai kerusakan jalan maka stationer jalan tersebut mempunyai kondisi permukaan jalan yang rata. Hal ini sejalan dengan penelitian dari (Tho'atin, Setyawan and Suprapto, 2016) dan (Psalmen Hasibuan and Sejahtera Surbakti, 2019)

\section{Kesimpulan dan Saran}

\subsection{Kesimpulan}

Kondisi jalan secara umum di jalan tol Pemalang-Batang masih baik hal ini dibuktikan dengan nilai PCI rata-rata sebesar 94,93 dan nilai IRI rata-rata sebesar 2,48 . Namun masih terdapat kondisi perkerasan yang rusak dibeberapa titik ruas jalan. Tidak ada pengaruh antara kondisi PCI dan IRI dengan kejadian kecelakaan di ruas Tol Pemalang-Batang hal ini terlihat dari kecelakaan yang terjadi di lokasi jalan dengan kondisi PCI dan IRI yang baik. Penyebabnya kecelakaan beragam mulai dari kurang antisipasi, ngantuk dan pecah ban.

\subsection{Saran}

Meskipun kondisi secara umum jalan tol Pemalang-Batang adalah baik, bukan berarti bebas dari kerusakan jalan. Masih terdapat beberapa ruas jalan di stationer tertentu yang kondisinya kurang baik, meskipun jumlahnya kecil. Namun untuk alas an keselamatan dan kenyamanan jalan tol, disarankan kepada pihak operator jalan tol untuk segera memperbaiki kondisi yang kurang baik tersebut sesuai dengan SPM jalan tol.

\section{UcapanTerima Kasih}

Penulis mengucapkan terima kasih kepada Direktur Politeknik Keselamatan Transportasi Jalan dan PT. PemalangBatang Toll Road (PT.PBTR) sehingga terlaksana penelitian ini sampai selesai. 


\section{Daftar Kepustakaan}

ARRB Group (2016) 'Hawkeye 2000 Series Manual', in.

Badan Pusat Statistik (2019) Perkembangan Jumlah Kendaraan Bermotor Menurut Jenis, 1949-2018. Jakarta: Badan Pusat Statistik.

BPJT (2018) Menyambung Negeri Meningkatkan Daya Saing.

Budiharjo, A. and Margarani, S. R. (2019) 'Kajian Penerapan Multi Lane Fee Flow (MLFF) Di Jalan Tol Indonesia', Jurnal Keselamatan Transportasi Jalan (Indonesian Journal of Road Safety), 6(2), pp. 1-14. doi: 10.46447/ktj.v6i2.27.

Fahza, A. and Widyastuti, H. (2019) 'Analisis Daerah Rawan Kecelakaan Lalu Lintas pada Ruas Jalan Tol Surabaya-Gempol.', Jurnal Teknik ITS, 8(1), pp. 54-59. doi: 10.12962/j23373539.v8i1.42123.

Faisal, R. et al. (2020) 'Perbandingan Metode Bina Marga dan Metode Pci (Pavement Condition Index) Dalam Mengevaluasi Kondisi Kerusakan Jalan tinggi karena terdapat dua Universitas negeri yaitu UNSYIAH dan UIN ARjalan ruas Jalan Tengku Chik Ba Kurma merupakan jalan kolektor .', Teras Jurnal, 10(1), pp. 110-122.

http://pbtr.co.id/v2/galeri (2020). Available at: http://pbtr.co.id/v2/asset/upload/image/1587709668_32e1e29dadaea818531 8.jpg.

Idris, M. and Santoso, I. (2004) Penanganan Lokasi Rawan Kecelakaan Lalu Lintas. Available at: http://www.pu.go.id/uploads/services/infopublik20120704151813.pdf.

Karim, F. M. A., Rubasi, K. A. H. and Saleh, A. A. (2016) 'The Road Pavement Condition Index (PCI) Evaluation and Maintenance: A Case Study of Yemen', Organization, Technology and Management in Construction: an International Journal, 8(1), pp. 1446-1455. doi: 10.1515/otmcj-2016-0008.

oto.detik.com (2020) Mobil Rusak karena Jalan Berlubang di Tol? Bisa Minta Ganti Rugi ke Pengelola. Available at: https://oto.detik.com/mobil/d5086712/mobil-rusak-karena-jalan-berlubang-di-tol-bisa-minta-ganti-rugike-pengelola.

Pembuain, A., Priyanto, S. and Suparma, L. B. (2019) 'Evaluasi Kemantapan Permukaan Jalan Berdasarkan International Roughness Index Pada 14 Ruas Jalan di Kota Yogyakarta', Teknik, 39(2), p. 132. doi: 10.14710/teknik.v39i2.21459.

Pradana, M. F., Budiman, A. and Andriyani, D. (2013) 'Analisis Kecelakaan Lalu Lintas Jalan Tol Studi Kasus Ruas Jalan Tol Serang Timur - Merak Km 72 - Km 98', Fondasi, 2, pp. 1-9.

Psalmen Hasibuan, R. and Sejahtera Surbakti, M. (2019) 'Study of Pavement Condition Index (PCI) relationship with International Roughness Index (IRI) on Flexible Pavement.', MATEC Web of Conferences, 258, p. 03019. doi: 10.1051/matecconf/201925803019.

Rahmawati, A. et al. (2018) 'Evaluasi Tebal dan Analisi Kerusakan Perkerasan Lentur Menggunakan Analisa Komponen, Austroads, Asphalt Institute dan Program Kenvape', Media Teknik Sipil, 16(2), pp. 79-85. Available at: http://ejournal.umm.ac.id/index.php/jmts/article/view/6428. 
Ramli, Y., Isya, M. and Saleh, S. M. (2018) 'Evaluasi Kondisi Perkerasan Jalan Dengan Menggunakan Metode Pavement Condition Index (Pci) (Studi Kasus Ruas Jalan Beureunuen - Batas Keumala)', Jurnal Teknik Sipil, 1(3), pp. 761-768. doi: 10.24815/jts.v1i3.10037.

Salamah, N., Rabbani, F. and Budiharjo, A. (2018) 'Analisis dan Penanganan Ruas Rawan Kecelakaan Lalu Lintas pada Lokasi Rawan Kecelakaan', Prosiding Simposium Forum Studi Transportasi antar Perguruan Tinggi ke21, (17), pp. 19-20. Available at: https://ojs.fstpt.info/index.php?journal=ProsFSTPT\&page=article\&op=view \&path\%5B $\% 5 \mathrm{D}=465$.

Samsuri, S. et al. (2019) 'Journal of Engineering and Technology Management', Journal of Engineering and Technology Vol. 01, No. 02, 2019 I 103-113, 01(02), pp. 103-113.

Sumaryoto (2010) 'Dampak Keberadaan Jalan Tol Terhadap Kondisi Fisik, Sosial, dan Ekonomi Lingkungannya', Journal of Rural and Development, 1(2), pp. 161-168.

Suprayitno, B. (2012) 'Privatisasi Jalan Tol Sebagai Solusi Dalam Mempercepat Terwujudnya Infrastruktur Jalan Tol Yang Memadai Di Indonesia', Jurnal Economia, 8(1), pp. 65-77. doi: 10.21831/economia.v8i1.822.

Tho'atin, U., Setyawan, A. and Suprapto, M. (2016) 'Penggunaan Metode International Roughness Index (Iri), Surface Distress Index (Sdi) Dan Pavement Condition Index (Pci) Untuk Penilaian Kondisi Jalan Di Kabupaten Wonogiri', Prosiding Semnastek, 0(0), pp. 1-9. Available at: https://jurnal.umj.ac.id/index.php/semnastek/article/view/685.

Tol, B. P. J. (2020) Jalan Tol Beroperasi. Jakarta, Indonesia: Badan Pengelola Jalan Tol.

Wirabrata, A. (2019) Dampak Pembangunan Jalan Tol Terhadap Sektor Lain, Ekonomi Dan Kebijakan Publik.

Wirnanda, I., Anggraini, R. and Isya, M. (2018) 'Analisis Tingkat Kerusakan Jalan Dan Pengarunya Terhadap Kecepatan Kendaraan', Jurnal Teknik Sipil, 1(3), pp. 617-626.

Zhao, B. and Nagayama, T. (2017) 'IRI Estimation by the Frequency Domain Analysis of Vehicle Dynamic Responses', Procedia Engineering. The Author(s), 188, pp. 9-16. doi: 10.1016/j.proeng.2017.04.451.

Zuna, H. T. (2016) 'Penentuan Atribut Pelayanan Jalan Tol Prioritas Dengan Pendekatan Customer Experience', Jurnal HPJI, 2(1), pp. 25-34. doi: 10.26593/jh.v2i1.2123.

Copyright (c) Anton Budiharjo, Dimas Wisnu Haryoko, Kornelius Jepriadi

Analisis Tingkat Kerusakan Jalan Tol - Anton Budiharjo, Dimas Wisnu Haryoko, Kornelius Jepriadi 